\title{
Clube de ciências e as tendências educacionais aplicadas no contexto regional Amazônico
}

\author{
Science club and educational trends applied in regional context Amazon \\ L.O. Silva ${ }^{1 *}$; S.C. Alves²; R.R. Farias ${ }^{2}$; R.J.M. Cruz ${ }^{2}$ \\ ${ }^{l}$ Centro de Ciências Sociais e Educação/Departamento de Ciências Naturais/Universidade do Estado do \\ Pará,66113-010, Belém, Pará,Brasil \\ ${ }^{2}$ Campus Universitário XVIII/Curso Licenciatura Plena em Ciências Naturais/Universidade do Estado do Pará, \\ 68400-000, Cametá, Pará, Brasil. \\ *luelyoliveira@hotmail.com
}

(Recebido em 26 de março de 2016; aceito em 17 de abril de 2016)

\begin{abstract}
Clube de Ciências é um ambiente pedagógico onde os graduandos e alunos têm oportunidade de elaborar pesquisas sobre ciências. Logo, o objetivo desse trabalho foi verificar de que forma o uso de tendências educacionais, utilizando o tema açaí pode contribuir para o processo ensino-aprendizagem de Ciências, no espaço do Clube de Ciências. Bem como, investigar o uso da interdisciplinaridade e contextualização que possibilite uma prática docente mais significativa valorizando o saber da região. As bases metodológicas da pesquisa se deu pela aplicação de uma pesquisa de campo realizada na Escola Municipal de Ensino Fundamental General Osório Cametá, Pará, Brasil (local do Clube de Ciências), com os alunos das $8^{\text {a }}$ Séries (sócios mirins participantes do Clube de Ciências), utilizando procedimentos como observações, questionários e prognósticos no intuito de se recolher dados da pesquisa. Neste desenvolvimento pode se visualizar a eficácia da utilização de metodologias como a experimentação, teatro, jogos, entre outros; dentro de uma ambientação sociocultural e interdisciplinar. Bem como a oportunidade de vivenciar ambientes alternativos de ensino e de popularização da ciência como os Clubes de Ciências que possibilita o aperfeiçoamento de atuais e futures professores, além de favorecer a interação alunoprofessor, onde ambos se encontram em um processo de construção de conhecimento cientifico justificado, elaborando pesquisas, desenvolvendo experimentos, criando projetos, sentindo-se autônomos e criativos e contribuindo positivamente para o progresso da ciência e da sociedade.

Palavras-chave: Clube de Ciências, Tendências Educacionais, Açaí
\end{abstract}

Science Club is an educational environment where students and graduates have the opportunity to elaborate research on science. Therefore, the aim of this study was to verify how the use of educational trends, using the theme açaí may contribute to the teaching-learning process of Science in space Science Club. As well as investigate the use of interdisciplinarity and contextualization that allows a more meaningful teaching practice valuing the knowledge of the region. The research methodological bases was due to the application of a field research conducted at the Municipal Elementary School General Osório Cametá, Pará, Brazil (site of the Science Club), with the students of the 8th grades (junior partners, participants of Science Club) using procedures such as observations, questionnaires and predictions in order to collect research data. This development can view the effective use of methodologies such as experimentation, theater, games and more; within a socio-cultural and interdisciplinary setting. As well as the opportunity to experience alternative learning environments and popularization of science as the Science Clubs that enables the improvement of current and futures teachers, and encourage student-teacher interaction, where both are in a process of justified scientific knowledge construction, developing research, developing experiments, creating projects, feeling autonomous and creative and contributing positively to the progress of science and society.

Keywords:Science Club, Educational Trends, Açaí

\section{INTRODUÇÃO}

O cenário construído no âmbito do Ensino de Ciências tem apontado para a utilização de Abordagens e Tendências Educacionais mais dinâmicas, socialmente significativas e motivantes, a serem aplicadas no processo de ensino-aprendizagem, nas escolas; no intuito de se formarem alunos-cidadãos proativos e crítico-reflexivos diante da realidade que os cercam. Dessa forma, este artigo permeia a Questão do Ensino de Ciências, perpassando o cenário 
educacional amazônico. Utilizando das Tendências Educacionais que propõem metodologias mais condizentes com as necessidades dos discentes, fundamentou-se no Movimento CTS (Ciência, Tecnologia e Sociedade) [1], se propõe um ensino interdisciplinar contextualizado [2], e uma experimentação baseada em uma perspectiva sociocultural [3]; a fim de se alcançar uma aprendizagem mais significativa [4]. Através da técnica de projetos, por meio das abordagens temáticas, vislumbra-se uma alternativa para um fazer educacional mais eficaz. Apropria-se também da ludicidade, a partir dos jogos didáticos, do teatro e da poesia; como uma abordagem a ser considerada no Ensino de Ciências, ao se objetivar uma formação mais global e humana.

O Ensino de Ciências, assim como o ensino de outras áreas do conhecimento humano, sofreu um rígido processo de sistematização que em sua estruturação histórica desencadeou uma mecanização do processo de ensino-aprendizagem. Isto acabou limitando algumas relevantes características humanas do processo educacional. Desta forma, questões como subjetividade, individualidade, experiências pessoais e sociais, não eram levadas em consideração no desenvolver do ensino do educando. Como coloca Zanon [5], "[...] O estudante, alijado à condição de "tábua rasa", era visto como sujeito passivo. Ensinar era visto como tarefa fácil, bastando dominar os conteúdos verdadeiros, prontos e acabados" [5].

No entanto, após várias discussões, propostas metodológicas, inovações no Ensino de Ciências e novas discussões, percebeu-se que se torna indispensável para um aprendizado efetivo a inserção de significado neste processo através de conexões com a pessoalidade e a sociabilidade dos estudantes.

A relevância, dos aspectos sociais e pessoais do indivíduo, deve ser considerada para que se concretize uma alfabetização científica, que é definida pelo próprio Chassot [6]: "[...] como o conjunto de conhecimentos que facilitariam aos homens e mulheres fazer uma leitura do mundo onde vivem"[6], por conseguinte, se é para esta leitura do mundo do educando que o Ensino de Ciências se prospecta, nada mais natural que busque neste universo, embasamento, também, para estruturar o próprio processo de ensino-aprendizagem.

Portanto, fez-se necessário uma metodologia ou metodologias que valorizem o saber e o fazer local. Uma forma de ensino que não considere "[...] o professor como o centro do saber e o aluno da ignorância" [7].

A aplicação do Clube de Ciências justifica-se por dar maior embasamento científico a essa abordagem metodológica, por funcionar como um laboratório de confluência de várias formas (jogos, brincadeiras, experimentação, teatro) de se ensinar Ciências. Neste sentido, pode-se verificar neste local de ensino, como o ensino de Ciências pode ser feito de várias maneiras que não a tradicional. Uma maneira que parte do princípio de que não se está construindo o novo, mas sobre o novo. O novo que o aluno traz consigo de casa, da rua, da família, da sociedade.

Considera-se ainda a Região Amazônica que é uma região muito rica, não somente na diversidade de ecossistemas e animais, mas e, principalmente, na diversidade da população amazônica e de sua cultura, o que faz com que seu povo seja singular. Dessa forma, assim como as outras regiões brasileiras, a Região Amazônica apresenta especificidades que devem ser consideradas nos planejamentos sociais, políticos, econômicos, ambientais e educacionais voltados para a região. É neste intento que Hage [8] discursa,

Diante de situações existenciais tão diversas que envolvem ecossistemas, biodiversidade, sócio-diversidade e tantos outros elementos que compõem o acervo de saberes, experiências, e tecnologias da região, é inadmissível que as políticas e as práticas curriculares vigentes continuem a se perpetuar desconsiderando essas especificidades que constituem as identidades culturais de nossa região [8].

Desse modo, é importante que sejam levados em consideração as especificidades que constituem as identidades da região, pois assim, o educando se sentirá como parte integrante do processo de elaboração do conhecimento.

A abordagem regional vem reestruturar a visão científica de mundo do educando, à medida que o permite visualizar sua realidade dentro dos conteúdos trabalhados na escola; essa 
contextualização regional propicia um aprendizado mais significativo e incentiva a valorização da cultura do educando.

Nesta acepção é que, quando se volta para o regionalismo amazônico, visualiza-se o valor que temáticas como o Açaí pode ganhar dentro do processo de desenvolvimento cognitivo dos aprendizes.

No Pará, essa palmeira tem grande importância no contexto social, econômico, político e histórico. Encontra-se "Presente na mesa da população, nas refeições diárias que vão desde o café da manhã até o jantar" [9]. Contudo, não é só na mesa dos paraenses que o açaí pode ser encontrado:

O açaizeiro (Euterpe olerácea Mart) é largamente utilizado na Amazônia, pelo homem rural e urbano. Ele pode ser usado na construção de casas, como adubo, alimentação, etc. A espécie é uma palmeira tipicamente tropical, crescendo em terrenos de várzea e nas margens dos rios de terra firme. Segundo Lacerda apud Bahia; Souza [9] "o açaizeiro regional sobressai-se em meio à abundância de recursos florestais da Amazônia, como fonte supridora de matériaprima para o setor industrial e produtor de alimentos para o homem"

Levando em consideração o valor regional dessa temática, ela se mostra como um tema bastante relevante e promissor para se trabalhar o Ensino de Ciências nas escolas da região. Além disso, esta temática apresenta imensa gama de conhecimentos formais que podem ser suscitados e trabalhados a partir de sua abordagem; indo deste, conhecimentos biológicos (o açaí enquanto planta), perpassando por conhecimentos históricos (como a lenda do açaí), até a produção artística (com poesias, músicas, artesanatos, entre outros, referentes a essa temática); entre outras diferentes áreas do conhecimento humano.

Sendo assim, o objetivo desta pesquisa foi verificar de que forma o uso de Abordagens e Tendências Educacionais, utilizando o tema: Açaí como "carro chefe", pode alavancar exponencialmente o processo de ensino e aprendizagem de Ciências, no espaço do Clube de Ciências. Além disso, investigar o uso da interdisciplinaridade e contextualização dentro do cenário sócio-econômico-cultural da região. Por outro lado, perceber a contribuição que o uso de técnicas de projetos junto as abordagens temáticas pode trazer para o ensino. Além de, inferir sobre o uso da experimentação no ensino de Ciências. Também, verificar quais os efeitos que os jogos didáticos, dinâmicas, teatro e poesia podem trazer para os educandos no sentido de aprendizagem, motivação, participação e interação.

\section{MATERIAL E MÉTODOS}

A pesquisa teve como lócus a Escola Municipal de Ensino Fundamental General Osório, localizada na Avenida Gentil Bittencourt, $\mathrm{S} / \mathrm{N}^{\circ}$, Bairro Central, Município de Cametá, Estado do Pará, escola que sediou o projeto Clube de Ciências. O público objeto da pesquisa foram os alunos do $9^{\circ}$ ano do Ensino Fundamental de Ciências, em uma amostragem de 25 alunos.

Os discentes participantes do Clube de Ciências eram denominados de sócio-mirins. O Clube desenvolveu-se, em sua maior parte, dentro da referida escola, bem como sua amostra final realizada pelos discentes para a comunidade local.

A investigação caracterizou-se pela pesquisa de campo [10], à medida que se baseia na observação da realidade. Utilizou-se, na pesquisa: prognósticos, observações e questionários aplicados no início, durante e no fim do projeto, a fim de se efetuar a coleta de dados. Também realizou-se uma pesquisa bibliográfica ex-post-facto, com o intuito de embasar o estudo realizado.

Os prognósticos e as observações realizadas com os educandos no decorrer do projeto, se deram através de conversas e dinâmicas que objetivavam visualizar suas opiniões, percepções e desenvolvimentos dentro do Clube. As anotações eram feitas em uma ata, na qual encontram-se descritas todas as aulas e demais considerações referentes ao projeto. Outrossim, aplicou-se 
junto aos alunos do Clube de Ciências um questionário final, a fim de se analisar as transformações ocorridas relativas às opiniões, percepções e aprendizados, frente às metodologias utilizadas.

Passou-se um período de 04 (quatro) meses com os discentes, experimentando metodologias educacionais; desta forma, a proposta ensejou uma pesquisa qualitativa e participante [11].

O Clube de Ciências funcionava aos sábados pela manhã, os professores que ministravam as atividades eram chamados de professores-estagiários e eram graduandos do Curso de Licenciatura Plena em Ciências Naturais da Universidade do Estado do Pará.

Sendo assim, a pesquisa ocorreu durante as aulas do Clube de Ciências que apresentavam sempre a mesma sequiência didática: começando com uma dinâmica de grupo que servia ou para introduzir o tema do dia, ou relembrar a aula do encontro anterior ou, simplesmente para motivá-los para a aula; em seguida explanava-se o tema do dia de forma sucinta, uma vez que, os conceitos, pertinentes aos conteúdos ministrados, seriam aprofundados dentro de alguma dinâmica, jogo, demonstração ou experimentação; e, em um terceiro momento fazia-se uma avaliação, através de jogos e dinâmicas que encerravam o encontro.

\section{RESULTADOS E DISCUSSÃO}

$\mathrm{Na}$ incessante busca por um ensino interdisciplinar e contextualizado, baseado na realidade sociocultural dos educandos, estruturou-se o projeto Clube de Ciências utilizando o açaí como tema gerador, a fim de se trabalhar os mais diversos conteúdos, das mais diferentes áreas do conhecimento, relacionando-os com a vida dos discentes. No intuito de analisar a validade dessa abordagem temática, realizou-se, inicialmente, uma dinâmica de prognóstico na aula inicial com o objetivo de visualizar quais conhecimentos os educandos supunham que poderiam ser abordados a partir da temática supracitada. As suposições feitas pelos alunos encontram-se expostas na Figura 1.

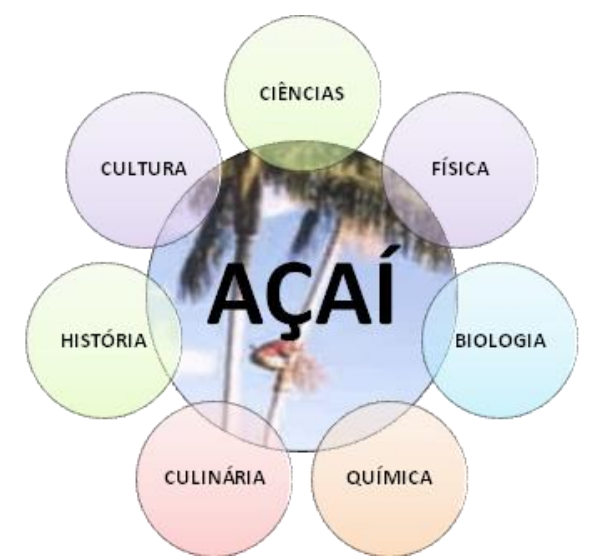

Figura 1: Organograma das Respostas dos discentes

Como se pode observar na Figura 1, os educandos indicaram várias disciplinas e conteúdos que poderiam ser abordadas a partir de alguma parte da palmeira do açaí (raiz, caule, frutos, entre outros), e da relevância sociocultural que a palmeira tem dentro dessa região (lendas, mitos, músicas, danças, economia, culinária, entre outros).

Logo, teve-se nessa observação o uso de abordagens temáticas para se trabalhar os conteúdos de Ciências nas escolas conforme proposto nos Parâmetros Curriculares para o Ensino Fundamental (PCNs) [12] de Ciências, buscando interdisciplinar com todas as disciplinas citadas na Figura 1.

Ademais, buscou-se visualizar a percepção e a opinião dos discentes em relação à utilização da abordagem temática utilizada no desenvolvimento do projeto. Para tanto, tem-se as respostas dos alunos quando inquirido, no questionário: "Você acha que o fato de termos usado o tema açaí como ponto de partida para aprendermos Ciência lhe ajudou para uma melhor compreensão?”. 
Obteve-se unanimidade positiva nas respostas, uma vez que, como coloca um aluno, "[...] o açaí é típico da nossa região e muito comum em nosso dia-a-dia" (aluno pesquisado - 14 anos). Além disso, segundo relato de outra aprendiz "[...] o tema açaí foi muito bom para a melhora da compreensão. Pois às vezes nós utilizamos ele e não sabemos os seus mistérios" (aluna pesquisada - 15 anos). Os alunos expuseram que o fato de conhecerem a temática, terem contato com ela no seu cotidiano, facilitou o aprendizado dos conteúdos científicos trabalhados no Projeto. Esse fato vem confirmar as proposições feitas por Mortimer; Machado [13]:

[...] as concepções trazidas pelos alunos à sala de aula são diferentes daquelas "cientificamente aceitas", no entanto, o conhecimento não é somente transmitido, mas construído pelos indivíduos, ou seja, o que o aluno já sabe influencia na sua aprendizagem [13].

Assim, quando se leva em consideração os conhecimentos e experiências primeiras dos educandos, busca-se colocar a seu favor fatores que pudessem interferir no processo de ensinoaprendizagem de forma negativa, à medida que a aprendizagem supõe uma mudança conceitual, que se define como as "[...] transformações e substituições de crenças e idéias prévias, de alunos sobre os domínios naturais e sociais por outras idéias mais sofisticadas (cientificamente aceitas)" [14]. Contudo, essa transposição de conceitos ocorre mais facilmente quando os discentes tem a oportunidade de relacionarem os novos conceitos as suas concepções prévias, através da contextualização dos conteúdos.

A partir das observações e conversas iniciais realizadas no projeto, percebeu-se que os alunos que se inscreveram para participar do Clube de Ciências, foram motivados, em sua grande maioria, pela proposta de se aprender Ciências de um modo diferente. A pergunta que os inquietou e pairava em suas mentes, era: "Como podemos aprender Ciências tendo a temática: Açaí, como ponto de partida?". Dessa forma, no primeiro encontro se visualizou alunos bastante curiosos e empolgados com a nova possibilidade de aprendizado.

Essa empolgação era oriunda do fato, de os alunos não gostarem ou, não compreenderem as aulas de Ciências tradicionais que tinham na escola. Isto pode ser exemplificado pelas respostas que deram ao serem questionados ao final do Projeto, "Antes de participar do Clube, o que você achava de estudar Ciências?”. As respostas são apresentadas na Figura 2

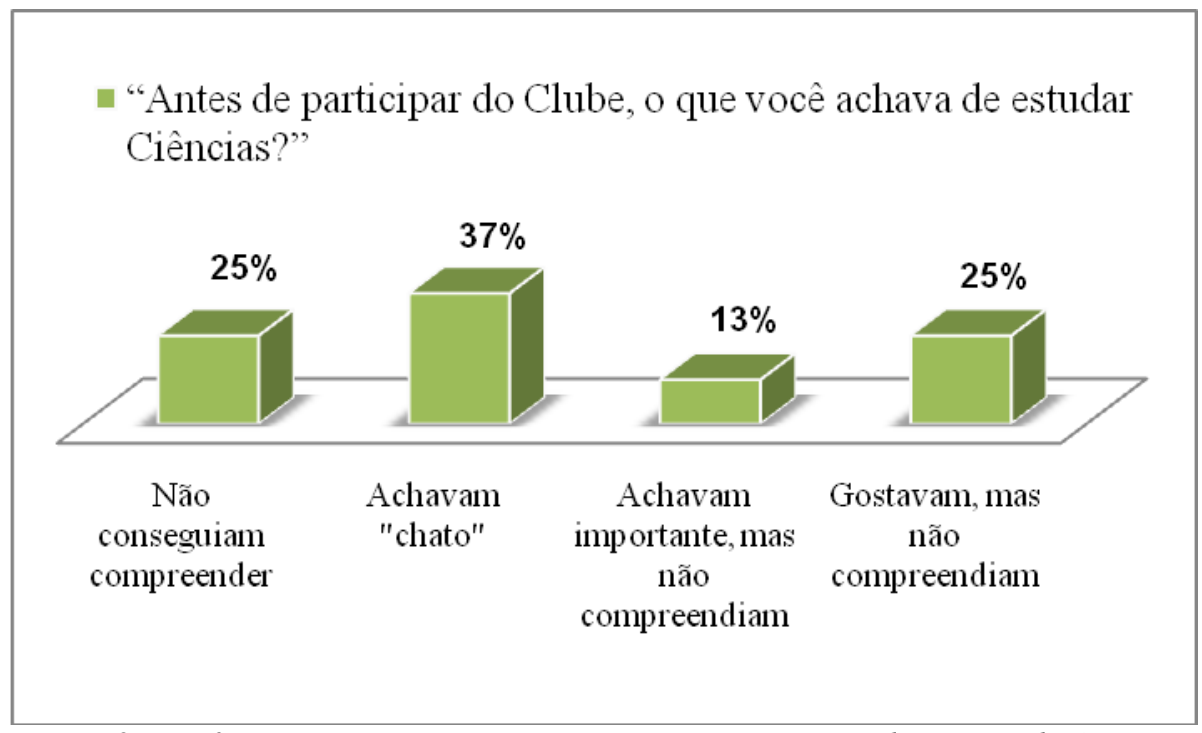

Figura 2: Gráfico quanto a compreensão e o interesse acerca do Ensino de Ciências.

A Figura 2 revela que a maioria dos alunos integrantes da pesquisa (63\%) não consegue compreender os conteúdos que lhes são ensinados em Ciências. E outra grande parcela (37\%), considera que a referida disciplina é um tanto quanto "chata". Contudo, ainda há os que gostem $(25 \%)$ e achem seu aprendizado importante (13\%), mesmo sem saber exatamente "Para o quê?". 
As respostas geradas a partir dos questionamentos direcionados aos alunos, revelam um ensino com pouco significado para o estudante, e que mesmo quando o discente demonstra gostar, e até considera importante o aprendizado acerca da referida disciplina, não consegue compreender os conteúdos que são trabalhados e nem a finalidade destes para sua vida.

[...] Muitos desses conteúdos, com o falso rótulo de necessários para a formação do espírito científico dos estudantes, organizam-se em uma determinada disciplina escolar, que muitas vezes se caracteriza como uma disciplina esotérica e que, por seu hermetismo, se torna (propositalmente) inacessível [15].

Esse hermetismo ocasionado nas Ciências devido à utilização de conteúdos que na maioria das vezes não têm relação com a realidade dos educandos ou, que não são relacionados com o que os discentes já conhecem, se tornando abstratos; acabam por afastar, excluir e até mesmo prejudicar o aprendizado do aluno.

Nesta reflexão caracteriza-se também um ensino tradicional. Um ensino que não deve ser mais a abordagem predominante utilizada nas aulas de Ciências. Uma vez que um ensino "[...] centrado na transmissão / recepção de conteúdos preestabelecidos, carentes de contextualização histórico-social e de significados conceituais" [16], não são suficientes para se alcançar uma aprendizagem que possibilite a formação do aluno enquanto cidadão crítico e analítico das relações e interações que realiza com seu ambiente físico e social, se tornando um agente de transformação; como propõe o movimento CTS (Ciência Tecnologia e Sociedade), uma nova tendência educacional que visa um Ensino de Ciências mais comprometido com a realidade e reais necessidades dos educandos.

Além de conteúdos descontextualizados, a prática de metodologias maçantes e abstratas tende a tornar o Ensino de Ciências tedioso e cansativo. Por outro lado, para se alcançar " [...] a superação do desinteresse demonstrado, de forma geral, pelos estudantes para com o Ensino de Ciências" [17], tem-se que buscar abordagens educacionais contextualizadas e interdisciplinares numa perspectiva sociocultural, que permita ao aluno uma visão, ao mesmo tempo, mais profunda e mais global de sua realidade. Nessa abordagem o aprendizado pode ocorrer de forma mais natural e significativa.

Indagou aos sócios-mirins se haviam gostado do Clube de Ciências, as respostas foram todas positivas e se estenderam, ainda, ao afirmarem que gostaram de mais de uma metodologia utilizada no projeto.As porcentagens seguem no organograma na Figura 3.

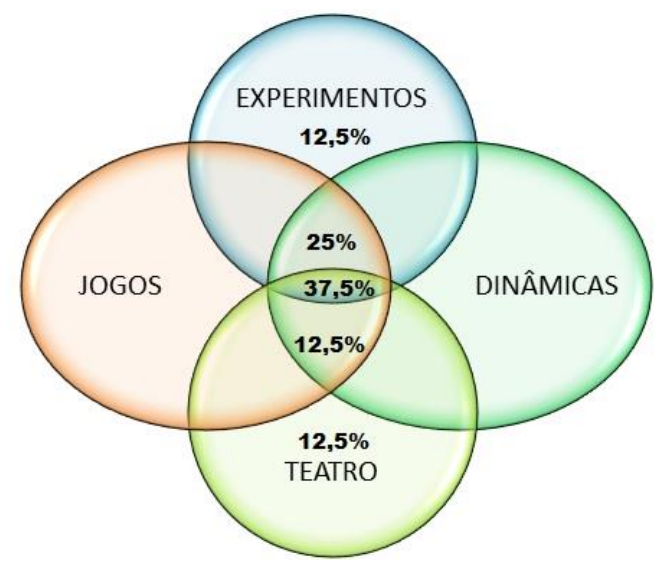

Figura 3: Organograma da opinião dos sócios-mirins

Observa-se na Figura 3 que a maior porcentagem dos alunos (37,5\%) gostou das quatro propostas metodológicas desenvolvidas ao longo do projeto; em seguida tem-se a preferência por jogos, dinâmicas e experimentos (25\%), bem como, em menor porcentagem, pelo teatro, jogos e dinâmicas $(12,5 \%)$ e, por fim visualiza-se uma predileção mais específica pelos experimentos $(12,5 \%)$ e pelo teatro $(12,5 \%)$. 
Quanto as atividades desenvolvidas no Clube de Ciências a Tabela 1 ilustra as diversas ações ministradas ao longo do projeto.

Tabela 1: Ações ministradas no Clube de Ciências

\begin{tabular}{ll}
\hline ATIVIDADE & AÇÃO \\
\hline EXPERIMENTOS & $\begin{array}{l}\text { Açaí como indicador ácido e base e Pilhas } \\
\text { alternativas. }\end{array}$ \\
JOGOS & $\begin{array}{l}\text { Jogo da trilha com Biomas Brasileiros, Quiz } \\
\text { ácido e base, Uno periódico e Jogo da } \\
\text { memória com as vitaminas. }\end{array}$ \\
DINÂMICAS & $\begin{array}{l}\text { Quebra Gelo, Dinâmica da Laranja, Dinâmica } \\
\text { do nó humano, Telefone sem fio e Bola na }\end{array}$ \\
TEATRO & cesta. \\
& A Lenda Indígena do Açaí \\
\hline
\end{tabular}

Além das metodologias mencionadas na Tabela 1, também se realizou dentro do projeto atividades com poesia e música; que tiveram grande aceitação dos educandos, os fazendo refletir criticamente sobre como a cultura do açaí é vista dentro e fora do Estado.

Com toda essa diversidade metodológica, os discentes ficavam curiosos e empolgados para a próxima aula, pois queriam saber que novidades os esperavam e quais conteúdos seriam trabalhados dentro dessa nova abordagem.

Assim, verifica-se a relevância da diversidade metodológica que é vista pelos alunos como algo positivo e motivante para sua aprendizagem. Esta reflexão, mostra que os próprios alunos requerem do professor uma postura inovadora, dinâmica e criativa frente a sua prática de ensino; no intuito de mediar um processo de ensino que permita a exploração de inúmeras possibilidades de interação, reflexão e ação dos discentes no mundo em que vivem. Conseqüentemente, "[...] Cabe ao professor esforçar-se por conhecer, adaptar-se e saber aproveitar as oportunidades" [18].

Ao final do projeto, foi proposta, aos alunos, a apresentação para a comunidade local das atividades desenvolvidas no Clube, em forma de amostra, onde apresentaram peça teatral, jogos didáticos, dinâmicas e experimentos.

Os alunos demonstram grande empolgação com a realização da amostra. Gostaram de poder mostrar o trabalho que realizaram no Clube de Ciências sentindo-se responsável por toda produção exposta.

Quando questionados, através do questionário aplicado, sobre suas opiniões a respeito da amostra, com a seguinte indagação: "Você gostou da amostra que foi apresentada ao final do projeto com os trabalhos realizados no Clube? Por quê?", ao que se obtiveram as seguintes respostas: "Eu amei porque falava sobre o açaí sobre a nossa cultura" (aluna pesquisada - 14 anos); "Não gostei, adorei porque foi muito legal e bem divertido. Nos ajudou a ver, a compreender e se interessar mais por várias coisas" (Aluna pesquisada - 15 anos). Assim, compreende-se, na fala das aprendizes, que os educandos, sentiram interesse pela amostra, assim como por todo o projeto, porque trabalhavam com algo que os mesmos já conheciam, fazia parte de sua cultura. Nesta perspectiva,

A contextualização visa dar significado ao que se pretende ensinar para o aluno [...], auxilia na problematização dos saberes a ensinar, fazendo com que o aluno sinta a necessidade de adquirir um conhecimento que ainda não tem [19].

Através da contextualização sociocultural, o educando sente mais necessidade de compreender conhecimentos propostos, pois o aprendizado destes o auxiliará a compreender sua própria vida.

O aluno precisa agir sobre o ambiente e os conhecimentos a serem aprendidos por ele, a fim de conseguir desenvolver um processo educativo efetivo e significativo. 
Percebeu-se, portanto, que os aprendizes gostaram da amostra e do projeto, pela diversidade metodológica. Metodologias que facilitaram seus aprendizados ao mesmo tempo em que os divertiam.

\section{CONCLUSÃO}

Na pesquisa realizada, ao se trabalhar no ambiente do Clube de Ciências, percebeu-se que se dispôs de uma maior liberdade metodológica, onde os professores têm a oportunidade de criar, testar e desenvolver práticas pedagógicas que venham ser mais condizentes com as problemáticas, inquietações e necessidades pertinentes à vida do educando.

Os experimentos, jogos, dinâmicas, teatro e poesia, metodologias utilizadas no projeto; permitiram aos educandos um alto grau de participação e profundo envolvimento no processo educativo, despertando-lhes grande interesse e motivação, ao trazer para os assuntos trabalhados, além da ludicidade, a possibilidade de elicitar seus primeiros aprendizados num processo de ensino-aprendizagem contextualizado nas suas experiências históricosocioculturais.

O uso de temas regionais abrange os aspectos característicos da metodologia temática, onde o tema regional se torna mais um fator positivo do processo, pois trata-se da experiência real vivida pelo aluno.

A diversidade metodológica foi um fator que gerou dinamismo ao ensino; conseqüentemente, acabou por facilitar a aprendizagem, uma vez que tirou a sensação de rotina que se vivencia nas escolas, e empregou certa aproximação com o mundo mais interativo e dinâmico que os educandos vivenciam diariamente. Essa diversidade foi apontada pelos alunos como algo motivante e instigante dentro do projeto.

Diante das limitações ocasionadas pelo sistema educacional, defende-se o fazer escolar em Ciências nas escolas brasileiras, a fim de se desenvolver um ensino mais motivante, participativo, dinâmico e significativo para a área das Ciências, concomitantemente, sendo um ambiente de exploração dos conteúdos científicos trabalhados nas salas de aula.

\section{AGRADECIMENTOS}

Ao Clube de Ciências da Universidade do Estado do Pará (Campus XVIII)

\section{REFERÊNCIAS BIBLIOGRÁFICAS}

1. Auler D, Bazzo WA. Reflexões para a implementação do movimento CTS no contexto educacional brasileiro. Ciência \& Educação, Bauru, v. 7, n. 1, 2001, p. 1-13.

2. Marcondes MER, Silva ELDA, Torralbo D, Akahoshi LEH, Carmo MP, Suart RC, Martorano SA, Souza FLde (2007a). Oficinas Temáticas no Ensino Público visando a Formação Continuada de Professores. São Paulo: Imprensa Oficial do Estado de São Paulo, 2007, 107 p.

3. Delizoicov D, AngottI JA, Pernambuco MM. Ensino de Ciências: fundamentos e métodos. São Paulo: Cortez, 2002, p. 223-233.

4. Moreira M A, Masini EFS. A aprendizagem significativa: A teoria de David Ausbel. Editora Moraes LTDA, SP, 1982.

5. Zanon LB, Maldaner OA. Fundamentos e propostas de ensino de química para a Educação Básica. Ijuí: Ed. Unijuí, 2008, 120p.

6. Chassot A. Alfabetização científica: questões e desafios para a educação. $5^{a}$ ed. Ijuí: Unijuí, 2011.

7. Pinheiro MdoSD. Currículo e seus significados para os sujeitos de uma escola ribeirinha multisseriada do Município de Cametá - Pará. Dissertação de mestrado apresentada à Universidade Federal do Pará. orientador, 2009, 205p.

8. Hage SM (Org.). Educação do campo na Amazônia: retratos de realidade das escolas multisseriadas no Pará. Belém: Gráfica e Editora Gutemberg Ltda, 2005, 300p.

9. Bahia PQ, Souza JEOde. Gestão logística da cadeia de suprimentos do açaí em Belém do Pará: uma análise das práticas utilizadas na empresa Point do açaí. VII Simpósio de Excelência em Gestão e Tecnologia,

2010 ,

$15 \mathrm{p}$.

Disponível

em: 
http://www.aedb.br/seget/arquivos/artigos10/149_Gestao\%20Logistica\%20da\%20cadeia\%20de\%20S uprimentos\%20do\%20Acai\%20-\%20modelo\%20final.pdf. Acesso em 23 de março de 2016.

10. Teixeira E. As Três Metodologias - Acadêmica, da Ciência e da Pesquisa. Editora Vozes, 2001, 104p.

11. Brandão CR (org.). - Pesquisa Participante: Um momento da educação popular. São Paulo: Brasiliense, 1999, p13.

12. Brasil MEC. Parâmetros Curriculares para o Ensino de Ciências. Secretária de Educação Fundamental, Brasília, MEC/SEF, 1997, 138p.

13. Machado AH, Mortimer EF. Química para o Ensino Médio: fundamentos, pressupostos e fazer cotidiano. In: Zanon LB, Maldaner OA. (Org.). Fundamentos e Propostas de Ensino de química para a Educação Básica no Brasil. Ijuí: Ed. Unijuí, 2007. p.21-41.

14. Castro SMVde, Freitas HdasG, Mendes IA, Pessôa MIF, Sousa AdosS, Sena HNS, Oliveira TRCde (Org.). Refletindo o Ensino de Ciências no Pará. Belém: Imprensa Oficial, 2002, 196p.

15. Chassot A. Alfabetização científica: uma possibilidade para a inclusão social. Revista Brasileira de

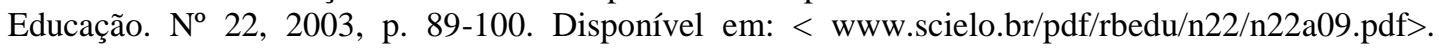
Acesso em: 25 de março de 2016.

16. Carvalho AMPde, Gil-Perez D. Formação de Professores de Ciências. São Paulo, Cortez, 1993.

17. Cunha MBda. O movimento Ciência/Tecnologia/Sociedade (CTS) e o Ensino de Ciências: condicionantes estruturais. Revista Varia Scientia. Artigos \& Ensaios, v. 06, n. 12, 2006, p. 121-134. Disponível em: <e-revista.unioeste.br/index.php/variascientia/article/download/.../1236>. Acesso em: 11 de março de 2016.

18. Terán AF, Tavares MTdosS. RECURSOS DIDÁTICOS: Uma Articulação Planejada no Ensino de Ciências. Revista Eletrônica Areté - Revista Amazônica de Ensino de Ciências. Manaus, v.3, n.5, 2010, p39-50. Disponível em: <www.revistas.uea.edu.br/download/revistas/arete/...3/arete_v3_n5.pdf>. Acesso em: 18 de março. 2016.

19. Ricardo EC. Implementação dos PCN em sala de aula: dificuldades e possibilidades. Caderno Brasileiro de Ensino de Física: Física na Escola. Florianópolis, v. 4, n. 1, 2003, 4p. 